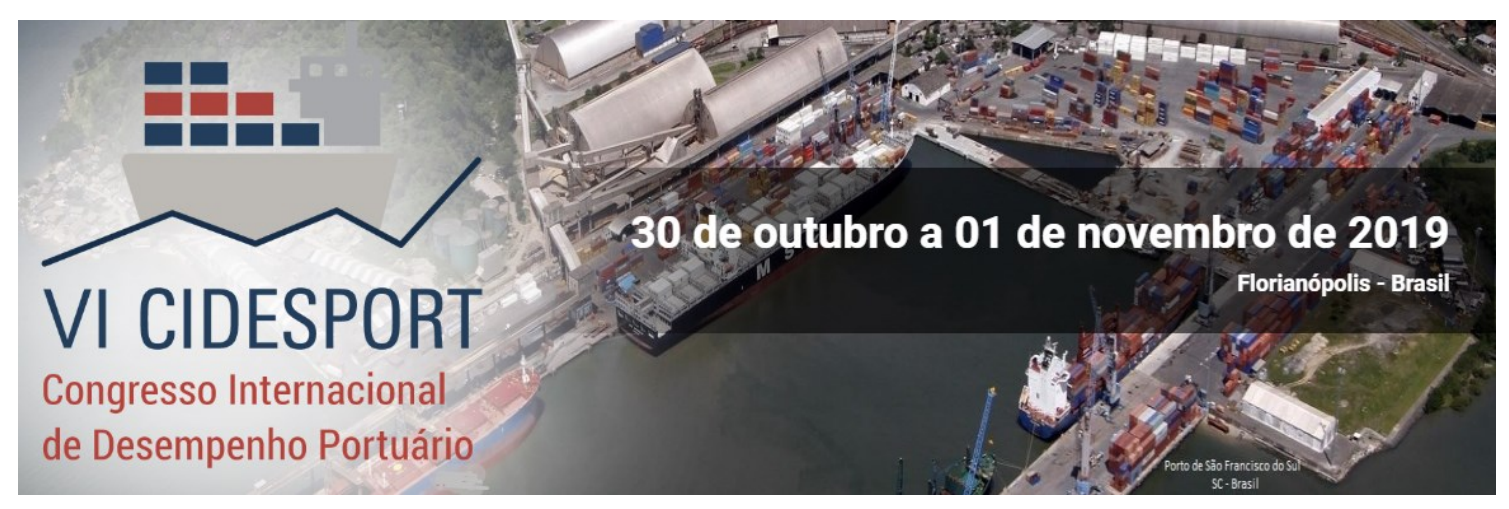

\title{
ÓLEO RESIDUAL - COMO O PORTO DO PECÉM TRANSFORMOU O PROBLEMA AMBIENTAL EM EDUCAÇÃO E GERAÇÃO DE RENDA NAS COMUNIDADES DA ÁREA DE INFLUẾNCIA.
}

\author{
Maria do Livramento de Barros Oliveira \\ MRS Ambiental, Porto de Pecém
}

\author{
Amanda Silva Bezerra \\ MRS Ambiental, Porto de Pecém \\ leda Passos Theophilo Gaspar de Oliveira \\ MRS Ambiental, Porto de Pecém \\ Sylvio de Campos Goncalves Neto \\ MRS Ambiental, Porto de Pecém \\ Franscisco Wilame Silva Amaral Júnior \\ MRS Ambiental, Porto de Pecém
}

\begin{abstract}
Resumo: O Porto do Pecém é administrado pela Companhia de Desenvolvimento do Complexo Industrial e Portuário do Pecém S.A (CIPP S.A) e é um terminal portuário localizado a $60 \mathrm{~km}$ de Fortaleza nos Municípios de São Gonçalo do Amarante e de Caucaia. Com a implantação do terminal portuário houve uma possível interferência nas atividades relacionadas a pesca artesanal devido a sobreposição direta ou exclusão, de áreas de pesca preferenciais ou rotas pesqueiras. Dessa forma, fez se necessário a implantação de um Programa de Compensação da Atividade de Pesca - PCAP. No contexto do PCAP dentro da linha de ação de geração de renda autônoma para a comunidade foi implantado a coleta e a comercialização de óleo residual nas três comunidades de influência do Porto do Pecém. De forma cultural, o óleo residual era usado durante as atividades de pesca e também descartado pela população em geral de forma indiscriminada contribuindo para a poluição dos mares. Portanto, os objetivos principais do projeto foram a destinação adequada dos resíduos de óleo e a geração de renda sustentável para a comunidade pesqueira. A metodologia de implantação dessa atividade consistiu em cinco etapas: pesquisa de campo; formação da equipe de coleta; instalação dos pontos de coleta; termo de compromisso e acompanhamento, monitoramento do processo e avaliação. A participação das partes interessadas mostrou-se eficaz nos primeiros anos de aplicação da prática de recolhimento de óleos residuais com reciclagem de 3690 mil litros coletados pela comunidade pesqueira em 2 anos. Os óleos coletados advêm principalmente de restaurantes do Cumbuco e Taíba e da área industrial do Pecém.
\end{abstract}

Palavras chave: Porto. Educação Ambiental. Reciclagem. Geração de Renda. Meio Ambiente.

\footnotetext{
${ }^{*}$ A revisão gramatical, ortográfica, ABNT ou APA foi realizada pelos autores.
} 


\section{CIDESPORT/2019}

Congresso Internacional

de Desempenho Portuário

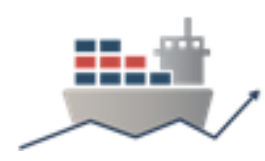

\section{INTRODUÇÃO}

O Porto do Pecém é administrado pela Companhia de Desenvolvimento do Complexo Industrial e Portuário do Pecém S.A (CIPP S.A) localizado a $60 \mathrm{~km}$ de Fortaleza nos Municípios de São Gonçalo do Amarante e de Caucaia, no Ceará. Esse porto foi construído para integrar o Complexo Industrial e Portuário do Pecém - CIPP que se encontra em constante expansão. A CIPP S.A é uma empresa de economia mista criada por meio de Decreto da Assembleia Legislativa do Estado do Ceará e sancionada pela Lei n. ${ }^{0} 12.536 / 95$, de 22 de dezembro de 1995, do Governo do Estado do Ceará. É vinculada à Secretaria de Desenvolvimento Econômico do Ceara e está constituída sob a forma de sociedade anônima, companhia aberta de capital autorizado.

O Porto do Pecém tem como missão oferecer soluções seguras e eficientes de logística de transporte multimodal de cargas, atuando como indutor de novos negócios, diretamente ou por meio de parcerias, promovendo o desenvolvimento sustentável para o Estado do Ceará. Além disso um dos valores organizacionais do Porto do Pecém é o compromisso socioambiental, que visa a adoção de práticas solidárias, com uso sustentável dos recursos em prol das gerações atuais e futuras. Dessa forma este terminal portuário possui várias atividades em prol do seu compromisso socioambiental.

O Porto do Pecém tem programas e projetos nos distritos Pecém e Taíba, onde estão localizadas a Colônia de Pescadores e Aquicultores Profissionais de São Gonçalo do Amarante (Z-06) e a Associação de Pescadores Profissionais da Praia de Taíba (ASPETA), que atua também como 'Capatazia' da Colônia Z-06, respectivamente, pertencentes ao município de São Gonçalo do Amarante, que possui $834,394 \mathrm{~km}^{2}$ e população de 43.947 habitantes (IBGE, 2010) ; e o Distrito de Cumbuco - onde está a sede da Colônia de Pescadores e Aquicultores Profissionais de Caucaia (Z-07), do Município de Caucaia, com $1.227,9 \mathrm{~km}^{2}$, o equivalente a $0,85 \%$ de todo o território do estado, e população de 362.223 habitantes (IBGE, 2010), além dos trabalhadores da obra.

Neste relatório técnico pretende-se analisar e apresenta uma das atividades que o Porto implantou e que faz parte das iniciativas de Desenvolvimento Sustentável Ambiental incentivadas de modo a gerar impacto positivo para o meio ambiente e para a comunidade das áreas de influência do empreendimento cumprindo com seu compromisso socioambiental.

\section{CONTEXTO}

A eficiência das operações portuárias decorrentes de uma estruturação competente, com modernos processos gerenciais, mão de obra e equipamentos adequados, acessos terrestres livres de confinamentos e custos altamente competitivos, somada a algumas vantagens logísticas (grande profundidade natural dos píeres de atracação, excelente posição geográfica, etc.) tornou o Complexo Industrial e Portuário do Pecém um importante centro de escoamento e recebimento de produtos do Estado do Ceará e de toda a Região Nordeste. Isso permitiu que o Porto do Pecém fosse inserido em rotas marítimas internacionais de navios de grande porte facilitando, assim, o desenvolvimento do comércio internacional em sua área de influência.

Para a instalação do Porto e suas ampliações foram realizados diversos estudos requeridos para a obtenção das licenças de instalação e operação expedidas pelo IBAMA. Nesses estudos foram apontados impactos negativos e positivos. 


\section{CIDESPORT/2019}

Congresso Internacional

de Desempenho Portuário

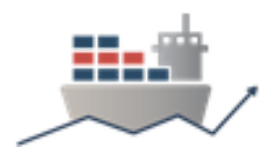

Cumprindo com sua obrigação legal e com seu compromisso socioambiental o Porto do Pecém realiza diversas atividades de incentivo ao desenvolvimento das comunidades regionais e ao desenvolvimento ambiental sustentável de forma a compensar e mitigar os seus possíveis impactos negativos.

Com a implantação do terminal portuário houve uma possível interferência nas atividades relacionadas a pesca artesanal devido a sobreposição direta ou exclusão, de áreas de pesca preferenciais ou rotas pesqueiras. Dessa forma, fez se necessário a implantação de um Programa de Compensação da Atividade de Pesca - PCAP. Este programa está inserido dentro do âmbito do Programa de Educação Ambiental do Porto do Pecém.

O PCAP conta com cinco linhas de ações: Projeto Segurança da Navegabilidade das Embarcações Pesqueiras e Localização de Pesqueiros; Projeto Qualificação Profissional e Geração de Renda Autônoma; Projeto Reforma de Jangadas; Projeto Encalhe de Jangadas; e Projeto Comercialização de Artefatos de Pesca.

No contexto do PCAP dentro da linha de ação de geração de renda autônoma para a comunidade foi implantado a coleta e a comercialização de óleo residual nas três comunidades de influência direta do Porto do Pecém.

Nas comunidades da Taíba e Pecém (distritos do município de São Gonçalo do Amarante) e do Cumbuco (distrito do município de Caucaia) ambos na área de influência do Porto do Pecém, no Ceará, foi evidenciado durante diagnóstico participativo com essas comunidades, a utilização de óleo vegetal pós fritura como meio atrator de peixes durante as atividades de pesca. Ainda no mesmo diagnóstico entendeu-se a necessidade de geração de renda autônoma para pescadores, marisqueiras e para as Colônias de Pescadores da região (Z-6 e Z-7).

Somando-se a isso, as comunidades da área de influência são essencialmente turísticas, o que corrobora com a presença de uma quantidade considerável de restaurantes na região. Portanto, durante a implantação do projeto era necessário identificar como era realizado o descarte do óleo utilizado e a disponibilidade de doação para os coletores associados ao projeto.

Portanto, os principais objetivos desse projeto além de gerar renda é promover a conscientização das pessoas da região sobre a importância do descarte correto do óleo residual. Neste relatório será apresentado e analisado os resultados da implantação dessa atividade.

\section{INTERVENÇÃO}

Dessa forma, foi identificado que a reciclagem de óleo residual tinha grande potencial de geração de sustentabilidade para as Colônias de Pescadores e como promoção de boas práticas ambientais na região. Assim, o Projeto de coleta do óleo residual (óleo vegetal de mesa usado) e o repasse para a instituições/ empresas para a destinação final adequada do resíduo com o objetivo de reciclagem e produção de sabão, biodiesel entre outros produtos foi iniciado. O intuito era que os recursos financeiros obtidos por meio desta boa prática fossem destinados parte para custear a logística e, a maior parte, como retorno para os colaboradores.

A destinação inadequada do óleo de cozinha é altamente prejudicial ao meio ambiente de diversas formas: quando jogado na pia (rede de esgoto) causa entupimentos que, não raro, levam ao uso de produtos químicos tóxicos para solução do problema; uma vez que se espalha na superfície dos rios e das represas causa danos à fauna aquática; no solo impermeabiliza-o contribuindo com enchentes ou 


\section{CIDESPORT/2019}

Congresso Internacional

de Desempenho Portuário

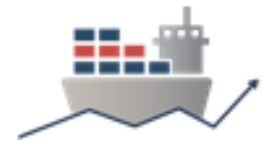

entra em decomposição, soltando gás metano durante esse processo e causando mau cheiro, além de agravar o efeito estufa (WILDNER, 2011).

Por outro lado, a coleta, filtragem e correta destinação para a reciclagem permite a retirada do óleo do meio ambiente, a produção de tintas, óleos para engrenagens e o de biocombustível que gera subprodutos como biodiesel e a glicerina, utilizado na fabricação de sabões (PARENTE, 2003), gerando, consequentemente, renda para os envolvidos no processo.

Para a implementação do Projeto foram necessários vários investimentos e ações para a completa estruturação do mesmo, desde a realização de pesquisa em estabelecimentos comerciais para levantamento do potencial de doação de óleo e cadastro de doadores, produção de material de divulgação (folders, imãs de geladeira), pintura e distribuição de tambores de coleta de 200 e de 50 litros e campanhas de mobilização social para a coleta do óleo residual, que ocorreu por meio agentes das próprias Colônias, de agentes ambientais do Programa de Educação Ambiental do Porto e por meio de parcerias com escolas ( Figura 1 a Figura 2).

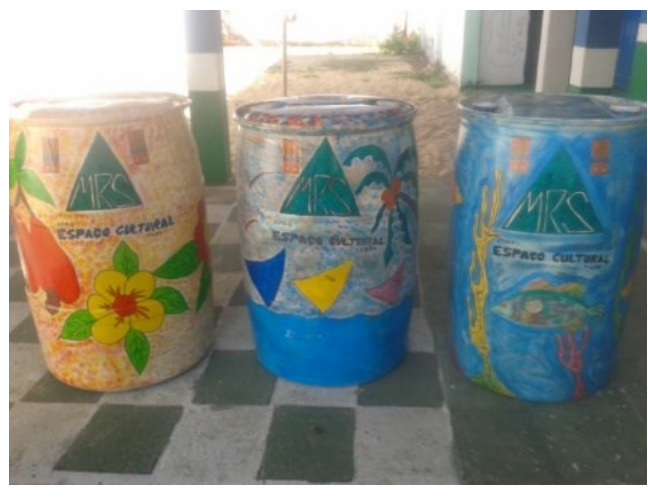

Figura 1 - Tonéis pintados para a coleta de óleo residual.

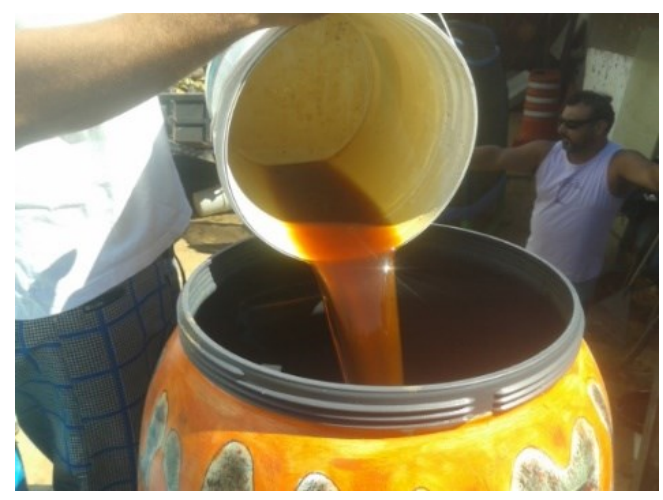

Figura 2 - Coleta do óleo residual.

O objetivo dessa atividade foi favorecer o aumento da renda familiar por meio da criação de alternativas de renda autônoma para estes trabalhadores e seus familiares, aliada a promoção da sustentabilidade ambiental e socioeconômica.

A metodologia de implantação dessa atividade consistiu em cinco etapas:

1. Pesquisa de campo: envolve visitas a residências, hotéis, restaurantes, pastelarias, autônomos (lanches de rua), empresas com restaurante, escolas etc com a finalidade de levantar a capacidade de produção das comunidades, mapear possíveis fornecedores e trabalhar a conscientização da população sobre o impacto do derramamento de óleos residuais na natureza.

2. Formação da equipe de coleta: compreende a divulgação da proposta, sensibilização dos pescadores, seleção dos responsáveis pela coleta e treinamento para a atividade.

3. Instalação dos pontos de coleta: implica na seleção e preparação do local e aquisição de tambores plásticos (estimados em 10 unidades de 50 litros e 9 unidades de 1.000 litros). 


\section{CIDESPORT/2019}

Congresso Internacional

de Desempenho Portuário

4. Termo de compromisso: são firmados termos de compromisso de fornecimento do óleo residual com fornecedores instituicionais e individuais, bem como o termo de repasse do óleo ao Coletor.

5. Acompanhamento, monitoramento do processo e avaliação: a equipe do Projeto fornece altervisão de todo o processo e empregam instrumentos de monitoramento que permitem obter dados da coleta (volume e espacialização), obtenção de renda e percepção dos coletores e da população envolvida.

A coleta e comercialização de óleo residual foi implementada como uma alternativa de geração de uma renda autônoma para trabalhadores da pesca, marisqueiras e para as colônias. A ação faz parte de uma ação estratégica do Projeto Qualificação Profissional e Geração de Renda Autônoma e é executada a partir da retomada da campanha permanente de coleta de óleo residual, visando reanimar a colônia e engajar os encarregados da coleta e os próprios presidentes das colônias do Pecém e do Cumbuco na coleta e destinação ambientalmente sustentável dos óleos residuais produzidos na região.

Buscando o engajamento das partes interessadas, foram realizadas reuniões com os compradores do óleo residual com os representantes de todas as colônias, tratando da apresentação do programa e a campanha de coleta, os papéis e responsabilidades no processo do coletor na comunidade, do representante da Colônia ou Capatazia e do programa com instalação dos pontos de coleta, treinamento de equipe, desenvolvimento de campanhas de conscientização e mobilização social.

O projeto buscou orientar a campanha nas comunidades por meio do cadastramento de novos pontos de coleta pelos agentes ambientais e incluindo a mobilização social em campanhas nas diversas atividades executadas pelo Programa de Educação Ambiental.

Foram adquiridos tambores de pequeno porte possibilitando a implantação de pontos de coleta e a instalação de locais de armazenamento temporário com capacidade de 1.000 litros em cada Colônia para posterior repasse para a instituição recicladora. Atualmente, a Associação CEEU (Centro de Educação e Evangelização Universal) e UNIPECEM são instituições responsáveis pela retirada do óleo coletado nas áreas que foram implantada essa iniciativa e pelo repasse ao representante emitindo, a partir do procedimento, o recibo.

\section{RESULTADOS OBTIDOS}

A participação das partes interessadas mostrou-se eficaz nos primeiros anos de aplicação da prática de recolhimento de óleos residuais. Os óleos coletados advêm principalmente de restaurantes do Cumbuco e Taíba e da área industrial do Pecém.

O número de pontos de coleta registrados cresceu gradualmente desde o ano inicial, com 26 pontos registrados em 2017, passando para 38 pontos em 2018 e mais dois em 2019, totalizando 40 pontos registrados para coleta do óleo atualmente. A quantidade de litros de óleo doados também se mostrou relevante, com 1250 litros doados em 2017, 1090 litros em 2018 e 1350 litros até o momento em 2019, totalizando 3690 litros.

Durante a implantação da atividade de coleta e venda do óleo residual foram feitas campanhas de conscientização ambiental. Com o passar do tempo não só as 


\section{CIDESPORT/2019}

Congresso Internacional

de Desempenho Portuário

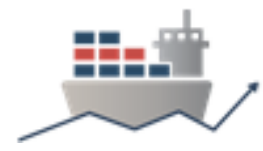

pessoas da comunidade que era público alvo desta ação, mas também pessoas que observaram o processo e ficaram atraída pela geração de renda extra começaram a coletar o óleo e fazer a destinação correta. Além disso, não é mais prática entre a comunidade pesqueira a utilização de óleo na atividade de pesca, sendo esse substituído por outros tipos de iscas.

O óleo vendido é corretamente destinado podendo se tornar em biodiesel, sabão ou outros materiais. Dessa forma, nota-se que o programa ambiental implantado pelo Porto do Pecém teve uma grande influência na mudança de hábito da população da região.

Em 2019 de modo a quantificar a eficiência desse programa que extrapolou a atuação das colônias de pescadores alvo inicial do projeto, foram realizadas pesquisas de campo na qual foi perguntada a quantidade média de litros de óleo coletado semanalmente. A partir deste dado foi possível fazer uma estimativa da quantidade de óleo que é corretamente destinada devido as ações realizadas pelo Projeto Do óleo Residual do Porto do Pecém. A Tabela 1 apresenta dados de uma pesquisa de campo realizada no período de 11 a 14 de julho de 2019 relativos à coleta de óleo residual nos restaurantes do entorno da vila do Cumbuco.

Tabela 1- Dados da pesquisa de campo nos restaurantes do entorno da vila Cumbuco no período de 11 a 14 de julho de 2019.

\begin{tabular}{|c|c|c|c|c|c|}
\hline $\mathbf{N}^{\circ}$ & Estabelecimento & $\begin{array}{l}\text { Quantidade } \\
\text { média de óleo } \\
\text { coletado(L) }\end{array}$ & $\begin{array}{c}\text { Total } \\
\text { médio } \\
\text { mensal } \\
\text { (L) }\end{array}$ & $\begin{array}{l}\text { Tipo de } \\
\text { descarte }\end{array}$ & $\begin{array}{c}\text { Arrecadação } \\
\text { média } \\
\text { mensal (RS) }\end{array}$ \\
\hline 1 & Barraca Milano & 20 por semana & 80 & Doação & 48 \\
\hline 2 & $\begin{array}{c}\text { Barraca Dona } \\
\text { Maria }\end{array}$ & 40 por quinzena & 80 & $\begin{array}{l}\text { Doação para } \\
\text { ama CEEU }\end{array}$ & 48 \\
\hline 3 & $\begin{array}{c}\text { Barraca Nossa } \\
\text { Casa }\end{array}$ & 20 por semana & 80 & Doação & 48 \\
\hline 4 & $\begin{array}{l}\text { Barraca Varanda } \\
\text { do Cumbuco }\end{array}$ & 15 por semana & 60 & Doação & 36 \\
\hline 5 & $\begin{array}{c}\text { Barraca Sabor da } \\
\text { Praia }\end{array}$ & 30 por semana & 120 & $\begin{array}{c}\text { Vendido para } \\
\text { uma empresa de } \\
\text { Fortaleza }\end{array}$ & 72 \\
\hline 6 & Petiscaria Exiu & $\begin{array}{c}5 \text { por semana } \\
\text { (baixa estação) e } \\
15 \text { por semana } \\
\text { (alta estação) }\end{array}$ & $\begin{array}{c}\text { Entre } \\
20 \text { a } 60\end{array}$ & $\begin{array}{c}\text { Doado para uma } \\
\text { pessoa da } \\
\text { comunidade }\end{array}$ & 12 \\
\hline 7 & $\begin{array}{l}\text { Barraca Cabana } \\
\text { do Cumbuco }\end{array}$ & 20 por semana & 80 & $\begin{array}{c}\text { Vendido para } \\
\text { empresa } \\
\text { chamada Green } \\
\text { Óleo }\end{array}$ & 48 \\
\hline 8 & Restaurante ACL & 15 por semana & 60 & Doação & 36 \\
\hline 9 & $\begin{array}{c}\text { Bar e } \\
\text { Restaurante } \\
\text { Muda }\end{array}$ & 10 por semana & 40 & $\begin{array}{l}\text { Vendido para } \\
\text { coleta em } \\
\text { Caucaia }\end{array}$ & 24 \\
\hline 10 & $\begin{array}{c}\text { Cowboy - } \\
\text { Churrascaria São } \\
\text { Jorge }\end{array}$ & 30 por mês & 30 & Vendido & 18 \\
\hline
\end{tabular}


VI CIDESPORT/2019

Congresso Internacional

de Desempenho Portuário

\begin{tabular}{|c|c|c|c|c|c|}
\hline 11 & $\begin{array}{c}\text { Restaurante } \\
\text { Israel }\end{array}$ & 5 por mês & 5 & $\begin{array}{c}\text { Doado para uma } \\
\text { pessoa da } \\
\text { comunidade }\end{array}$ & 3 \\
\hline 12 & $\begin{array}{c}\text { Bar e } \\
\text { Restaurante } \\
\text { Nithai } \\
\end{array}$ & 10 por semana & 40 & Doação & 24 \\
\hline 13 & $\begin{array}{c}\text { Bar e } \\
\text { Restaurante } \\
\text { Chezmark }\end{array}$ & 10 por semana & 40 & Doação & 24 \\
\hline 14 & Barraca Casulo & 20 por mês & 20 & $\begin{array}{c}\text { Doação para } \\
\text { Colônia do } \\
\text { Cumbuco }\end{array}$ & 12 \\
\hline & \multicolumn{2}{|c|}{ Projeção mensal } & 735 & - & 453 \\
\hline & \multicolumn{2}{|c|}{ Projeção anual } & 8820 & - & 5436 \\
\hline
\end{tabular}

Observando os dados obtidos por meio da pesquisa de campo e da quantificação do óleo residual coletado e vendido nota-se que os resultados são significativos. Por ano, somando a projeção e os dados já coletados toda a coleta realizada na região será de mais 10.000 litros de óleo corretamente destinados.

Segundo a Resolução Conama 357/2005, legislação vigente utilizada em análises de qualidade de água, em seu artigo 34 afirma que a quantidade máxima de óleo e graxas (vegetal ou animal) é de $50 \mathrm{mg} / \mathrm{L}$. Considerando assim esse valor como o mais restritivo possível, é permitido aproximadamente uma gota de óleo por litro. Dessa forma, em tese um litro de óleo poluiria 20.000 litros de água. Salienta-se que para rios classe 1, 2 ou 3 a presença de óleo precisa ser virtualmente ausente, não estabelecendo valores quantitativos para esta definição.

Cruzando os dados legislação vigente de tolerância de óleos e graxas com a quantidade de óleo projetada que poderia estar sendo descartada inadequadamente nos rios e mar, pode se concluir que o potencial de poluição sem a implantação do Projeto de óleo residual seria de 200.000 .000 litros de água.

É importante salientar que antes das atividades implantadas pelo Porto do Pecém não era realizado nenhum tipo de coleta de óleo residual na região e na maioria dos casos, como apontados nos diagnósticos realizado para a implantação do Porto, eram possivelmente inadequadamente destinados.

Outro ponto importante e que é um dos principais objetivos desse projeto é a geração de renda. As empresas responsáveis pela retirada do óleo e a destinação repassa ao representante dos pescadores no valor de $R \$ 0,60 /$ litro. O pagamento é realizado no momento da coleta considerando a quantidade de litros de óleo isento de água e sujeira. Apesar de numericamente não ser grande, quando somado o valor anual e a renda per capita da comunidade local, essa valor se torna significativo como complementação de renda.

\section{CONCLUSÕES}

A reciclagem do óleo residual tem gerado renda para a comunidade pesqueira dos distritos de Taíba, Pecém e Cumbuco de forma crescente desde 2017 e incentivou o desenvolvimento sustentável da região, diminuindo o potencial poluidor com a destinação adequada dos resíduos de óleo e a implementação de boas práticas, inclusive durante a pesca. 


\section{CIDESPORT/2019}

Congresso Internacional

de Desempenho Portuário

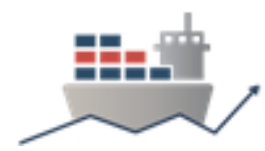

Os objetivos do projeto foram extrapolados, pois a população não somente pesqueira dos distritos foi sensibilizada por meio das palestras e das divulgações do potencial poluidor, além da visualização de resultados financeiros como incentivador da reciclagem do óleo residual.

Dessa forma, é possível afirmar que o Projeto de Reciclagem de Óleo foi uma iniciativa de impacto sustentável com melhoria socioeconômica da região que proporcionou a mudança de hábito da população da área de influência do Porto do Pecém e o desenvolvimento socioambiental da região.

\section{REFERÊNCIAS}

PARENTE, E. J. S. Biodiesel: uma aventura tecnológica num país engraçado. Fortaleza. Unigráfica, 2003.

WILDNER, L. B. A., 2011. Reciclagem de óleo comestível e fabricação de sabão como instrumentos de educação ambiental. Rio Grande do Sul. Monografia de Especialização, Universidade Federal de Santa Maria, Programa de Pós-Graduação em Educação Ambiental. 